признания должника банкротом. В случае пропуска этого срока по уважительной причине он может быть восстановлен судом.

Важно отметить, что заявление о привлечении контролирующего должника лица к субсидиарной ответственности не может быть подано после завершения конкурсного производства.

Таким образом, пунктом 2 и пунктом 4 статьи 10 Закона о банкротстве установлены и определены основополагающие условия и основания привлечения контролирующих должника лиц к субсидиарной ответственности.

Установление судом всех условий, необходимых для разрешения дела, в том числе таких как определение надлежащего лица, имеющего право обращаться в Арбитражный суд с соответствующим заявлением, определение надлежащего субъекта, привлекаемого к ответственности, установление доказанности обстоятельств дела, подлежащих обязательному доказыванию, приводит к вынесению судом правосудного акта.

Вместе с тем важно отметить, что специфика доказывания по каждому из оснований, установленных выше обозначенными пунктами статьи 10 Закона о банкротстве различна, что обуславливает необходимость применения заявителем по делу различных подходов к доказыванию.

1. Бакулин, А.Ф. О привлечении контролирующих должника лиц к субсидиарной ответственности / А.Ф. Бакулин, Ю.А. Вопиловский, С.В. Ремезова. - Арбитражный управляющий, 2013. - N 5. - С. 38.

2. Ст. 10 Федерального закона от 26.10.2002 N 127-Ф3 «О несостоятельности (банкротстве)» ред. от 29.12.2014. Доступ из справочно-правовой системы Консультант Плюс.

3. Постановление ФАС Поволжского округа от 07.11.2012 по делу N А57-156Б/06. Доступ из справочно-правовой системы Консультант Плюс.

\title{
Кулеев В.Я. \\ Проблемы применения средств обеспечения режима в исправительных учреждениях уголовно-исполнительной системы
}

Владимирский юридический институт ФСИН России (Россия, Владимир)

doi: $10.18411 / \mathrm{j}-07-2021-88$

\section{Аннотация}

В данной статье рассматриваются проблемы применения средств обеспечения режима в исправительных учреждениях уголовно-исполнительной системы, в частности вопрос доказуемости совершения преступления.

Ключевые слова: уголовно-исполнительная система, исправительные учреждения, сотрудник администрации, публичность.

\section{Abstract}

This article discusses the problems of using the means of ensuring the regime in correctional institutions of the penal system, in particular, the issue of provability of the commission of a crime. publicity.

Keywords: penitentiary system, correctional facility, administration employee,

В настоящее время Уголовно-исполнительная система (далее УИС) обеспечивает исполнение наказания в отношении лиц, совершивших преступления. От степени тяжести Уголовный кодекс Российской Федерации (далее УК РФ) 
регламентирует меры наказания касательно каждого преступления. На основании этого УИС реализует меры по исправлению осужденных. В ряде случаев, судом выносится приговор о назначении наказания, не связанного с лишением свободы, в этом случае на УИС не возлагается такое большое количество обязанностей как с исполнением наказаний, связанных с лишением свободы.

На исправительные учреждения (далее ИУ), исполняющие наказание в виде лишения свободы возлагаются обязанности по предоставлению благоприятных условий содержания, предоставления всех вещей и предметов, установленных законодательством, а в случае наличия заболевания у осужденных, еще и предоставление медпомощи. В случаях касающихся тяжких заболевания, требующих стационарного лечения, осужденного этапируют в специализированное учреждение.

Больным, лишенным свободы, оказывается медпомощь, а также услуги медицинского характера, направленные на его скорейшее выздоровление. Для лечения создаются благоприятные условия и происходит изоляция больного, для ликвидации возможности распространения болезни.

УИС идет на пути гуманизации. Для осужденных создаются все условия для того, чтобы они, по отбытию срока наказания, не потерялись в ритме жизни социума, который ускоряется с каждым. Осужденные получают все, что им необходимо. В процессе нормотворчества произошла декриминализация некоторых статьи УК РФ, в соответствии с чем в ИУ происходит уменьшение численности лиц, отбывающих наказание. Так в 2008 г. в исправительных учреждениях всех видов содержалось 734 тыс. человек, а в 2010 г. - 696 тыс. человек, причем эта тенденция сохраняется и поныне (2012 г. - 585 тыс., 2015 г. - 551 тыс., 2017 - 495 тыс. чел.), а в 2020 году численность осужденных, отбывающих наказание в местах лишения свободы по состоянию на 01.01.2021 снизилась до 378668 человек при лимите 591117 мест[1].

Число осужденных к лишению свободы также снижается: по данным Судебного департамента при Верховном суде РФ, к лишению свободы на срок в 2008 г. было осуждено 316146 человек, в 2010 г. - 276570 человек, в 2015 г. — 220488 человек, в 2017 г. - 208233 человек [2].

В соответствии с тем, что количество осужденных, отбывающих наказание в виде лишения свободы, уменьшается, происходит и уменьшение кадрового состава учреждений и ликвидируются учреждения. Назвать данные уменьшения пропорциональными не получается.

Как утверждал Владимир Винницкий «Несомненно, одним из главных условий решения проблемы является кадровое обеспечение пенитенциарной системы. В данный момент ФСИН испытывает серьезные кадровые проблемы - это дефицит сотрудников, их профессиональная подготовка и общий культурный уровень. Штатная численность персонала УИС, финансируемого из средств федерального бюджета, составляет примерно 296 тысяч человек, в том числе аттестованных сотрудников - 225 тысяч человек (кроме того, переменного состава - 6,6 тысячи человек). При этом дефицит кадров в отдельных учреждениях составляет от семи до 10 процентов. Наиболее остро обстоят дела с обеспечением кадрами медицинских учреждений ФСИН»[3].

Поскольку мы сталкиваемся с картиной нехватки сотрудников в большинстве учреждений. На действующих сотрудников возлагается большое количество обязанностей. И задержки на рабочем месте везде стали нормой. Сейчас мы видим картину того, что государство оказывает помощь осужденным, предоставляет им удовлетворительные условия отбывания наказания, реализует меры по минимизации ограничений, возложенных на осужденных. Однако в этой гонке за гуманизмом, упустили важную деталь. Решая вопрос об осужденных, забыли о тех, кто реализует правила и нормы. В равной степени забыли о сотрудниках. Да, реализуются меры по улучшению, однако можно ли между решенными вопросами об осужденных и вопросами о сотрудниках поставить знак равно? Я считаю, что нет, ибо большая часто 
сотрудников находятся на рабочем месте, выполняя поставленные задачи и по окончанию рабочего дня. Работа сотрудников из непосредственного оказания помощи осужденным и решении их вопросов превратилось в бюрократию. В постоянное ведение записей и предоставление отчетов. Отчетов во всех сферах деятельности. Учреждения УИС превратились в некий офис. В связи с чем сотрудникам зачастую приходится задерживаться на рабочих местах, для отражения результатов работы в письменном виде.

Одна из проблем касается оперативной работы. Главной задачей оперативных отделов ИУ является контроль спокойной обстановки в учреждении, отсутствие запрещенных предметов, а также отсутствие либо пресечение преступлений. Однако из-за того объема документооборота, возлагаемого на каждого сотрудника, реализация главной цели в рамках рабочего времени практически не достижима. Соответственно мы имеем картину, постоянных переработок. Однако выполнение поставленных задач сотрудниками ИУ осуществляется по своей воле, так как во главу встает вопрос об ответственном подходе каждого сотрудника к своим должностным обязанностям.

Из-за большого количества бумажной отчетности деятельность сотрудников не может быть полноценной. Во главу угла встает вопрос бюрократии. И данная проблема практически во всех отделах. Погружаясь в рутину деятельности ИУ замечаешь, что бюрократия занимает одно из главных мест в системе задач.

Одной из основных проблем в организации деятельности ИУ можно выделить следующую, несмотря на то, что численность осужденных с каждым годом уменьшается в связи с декриминализацией некоторых статей УК РФ, требования к раскрываемости преступлений в ИУ не снизились. От сотрудников, а в частности от оперативных сотрудников требуют постоянной раскрываемости преступлений. С учетом постоянного прироста либо в крайнем случае сохранения показателей. Данные требования заставляют искать новые пути привлечения к ответственности. Оперативные сотрудники должны искать любые поводы и возможности, для привлечения к ответственности, порой погоня за требуемым результатом может даже привести к провокации осужденных. Однако нередки случаи, когда осужденных не привлекают к ответственности, в связи с существующими пробелами в законодательстве. Примером служат ситуации, когда осужденный, находясь в запираемых помещениях, отказывается выполнять законные требования сотрудников администрации, сопровождая свои действия оскорблениями. Сотрудниками администрации до осужденного доводится, что его высказывания подпадают под статью 319 УК РФ, согласно которой публичное оскорбление представителя власти при исполнении своих должностных обязанностей или связанных с ним наказывается штрафом, обязательными работами либо исправительными работами. В связи с чем встает вопрос доказуемости публичного оскорбления представителя администрации, поскольку в момент оскорбления в коридоре другие осужденные не находятся, с целью недопущения противоправных действий, а сотрудники в данном случае не подпадают под публичность. При допущении оскорбления представителя власти происходит сбор материалов, однако другие осужденные, находящиеся в запираемых помещениях, подтверждать факт оскорбления, как правило, отказываются, в связи с так называемой «солидарностью» к другим осужденным. В этом случае публичность имеет место быть, так как осужденные могут слышать оскорбление представителя власти, однако процесс доказуемости данного деяния усложняется. Можно сказать, что в этом случае статус сотрудника не соответствует статусу человека, так как сотрудники не подпадают под публичность.

В результате чего, происходит сбор материалов, однако отсутствие показаний осужденных дает основание для отказа в возбуждении уголовного дела. В связи с чем осужденные, рассчитывая на так называемую «солидарность» допускают оскорбление представителей администрации, зная что негативных последствий для них не будет. 
Факт оскорбления имеет место быть, однако факт публичности в присутствии сотрудников администрации отсутствует.

В связи с чем, в целях совершенствования применения такого средства обеспечения режима как оперативно-розыскная деятельность рекомендуется статью 319 УК РФ дополнить следующими словами: «публичное оскорбление представителя власти - это унижение чести и достоинства представителя власти, выраженное в неприличной форме (словесно, жестами, письменно и т.д.) в присутствии других лиц, в число которых подпадают любые лица, в том числе представители власти, с целью либо нарушения нормальной деятельности органов власти, либо ущемления их авторитета, а равно унижения чести и достоинства конкретного представителя власти».

Таким образом, следует сделать вывод, что в настоящее время мы видим картину, когда сотрудники ИУ осуществляют большое количество обязанностей, что приводит к задержке на рабочих местах. Также мы видим, что реализация мер, направленных на исполнение наказаний в виде лишения свободы не может быть осуществлена в полной мере. В случае урегулировании данных проблем содержание осужденных в ИУ будет реализовывать свои задачи - исполнение наказаний.

$$
* * *
$$

1. Сайт Федеральной службы исполнения наказаний: https://fsin.gov.ru/budget/info.php (дата обращения 19.04.2021)

2. Аналитический доклад о состоянии уголовной политики в Российской Федерации // O законодательном обеспечении уголовно-правовой политики в Российской Федерации. - М., 2018. - C. 187 .

3. Электронное периодическое издание от 26.04.2018. Официальный сайт Общественной палаты Российской Федерации. (дата обращения 25.06.2021).

\section{Магомедова Е.А., Зайцева М.А., Воробьева М.О. \\ К вопросу о понятии и принципах государственной политики противодействия коррупции}

ФГБОУ ВО «Калужский государственный университет им. К.Э. Циолковского» Калужский институт (филиал) АНО ВО Московского гуманитарно-экономического университета (Россия, Калуга)

doi: $10.18411 / \mathrm{j}-07-2021-89$

\section{Аннотация}

В статье дается характеристика понятия и принципов государственной политики противодействия коррупции. Анализируются различные подходы к содержательному наполнению данного феномена, а также раскрываются его принципы, закрепленные в отечественном законодательстве. Делается вывод о достижении высокой эффективности проводимой государственной политики противодействия коррупции при условии реализации данных принципов в практике её осуществления.

Ключевые слова: государственная политика, противодействие коррупции, принципы, отечественная правовая система, российское законодательство, законность.

\section{Abstract}

The article describes the concept and principles of the state anti-corruption policy. Various approaches to the content content of this phenomenon are analyzed, as well as its principles enshrined in domestic legislation are revealed. The conclusion is made about the achievement of high efficiency of the state anti-corruption policy, provided that these principles are implemented in the practice of its implementation.

Keywords: state policy, anti-corruption, principles, domestic legal system, Russian legislation, legality. 